\title{
Human Carcinogenesis: Toward a Unified Theory
}

\author{
Briana Marshall, Doug Dix \\ Department of Health Science and Nursing, University of Hartford, West Hartford, USA \\ Email: Dix@hartford.edu
}

How to cite this paper: Marshall, B. and Dix, D. (2017) Human Carcinogenesis: Toward a Unified Theory. Open Access Library Journal, 4: e3707. https://doi.org/10.4236/oalib.1103707

Received: June 2, 2017

Accepted: July 22, 2017

Published: July 25, 2017

Copyright $\odot 2017$ by authors and Open Access Library Inc.

This work is licensed under the Creative Commons Attribution International License (CC BY 4.0).

http://creativecommons.org/licenses/by/4.0/

\begin{abstract}
If either chance or environmental exposure was the dominant carcinogen, cancer risk would increase continuously with age, but it doesn't. For all cancers studied, risk exhibits three phases: 1) Low risk at young ages, followed by 2) an increase in risk to a maximum at some later age, followed by 3) a plateau or decline in risk at advanced ages. Only a genetically-determined discontinuous process can explain this pattern. We analyzed differences in risk between tissues of tumor origin and between geographic locations, genders, races, and ethnicities for clues. Our analyses suggest that normal tissue differentiation is safe, but inadequate. At some critical age, regeneration or dedifferentiation is required and this is an invitation to carcinogenesis. Upon reaching this critical age, risk varies with the size of a target, which may correspond to the number of regenerating or dedifferentiating stem cells. Cancer incidence rates were analyzed for melanoma and cancers of the mouth, esophagus, stomach, small intestine, colon, rectum, liver, pancreas, larynx, bronchus, breast, and kidney in populations distributed worldwide and within the United States in two time eras. Over all cancers, in all populations, and both eras, the difference in age-specific rates between ages 50 and 40, d50 - 40, correlated strongly with age-standardized rates. Differences in d50 - 40 correlated strongly with differences in age-standardized rates between genders, races, and ethnicities. We suggest that, for the cancers studied, the critical age occurs between 40 and 50. If environmental exposure or segregating genes was the dominant carcinogen, the rank order of cancer risk between tissues of tumor origin would vary from one geographic location to another, because environment and segregating genes vary between geographic locations. Such variation was observed between rank order in Japan and rank order in other countries, but not between rank orders in the other countries. We suspect, therefore, that environment or segregating genes play an important role in determining the difference in rank order of risk for the tissues of tumor origin between Japan and other countries. If chance or environmental exposure was the dominant carcinogen, cancer risk would correlate strongly between pairs of cancers across populations, but it doesn't. Coefficients of risk between pairs of cancers
\end{abstract}


are, typically, moderate at best. Only mouth, larynx, bronchus, and kidney show strong coefficients. By our measures, cancer risk from aging exceeds cancer risk from other-than-aging causes in all populations in both eras. We suspect that the aging risk is determined by genes that are common to all members of our species, and we suggest that inhibiting tissue injury and unnecessary growth will reduce cancer risk.

\section{Subject Areas}

Public Health

\section{Keywords}

Carcinogenesis, Epidemiology, Genetics, Aging, International

\section{Introduction}

The pathway to cancer remains elusive. Tomasetti and Vogelstein concluded that chance was dominant [1]. But critics objected [2]. Wu, et al. concluded that exposure to environmental agents was dominant [3]. But both chance and exposure act continuously. If either was dominant, risk of a cancer diagnosis would increase continuously, but it doesn't. For all cancers studied, risk exhibits three phases: an early period of negligible risk, followed by an increase in risk to a maximum, followed by a plateau or decline in risk with further advance in subject age [4] [5]. For most common cancers, risk of a diagnosis is minimal below age 30. For these cancers, something about aging beyond 30 seems essential.

But aging doesn't occur by chance, and is only modestly influenced by the environment. Life expectancy is species specific, suggesting that aging is genetically programmed [4]. Genes were dismissed as dominant carcinogens because twin studies showed concordance among monozygotic twins to be only slightly greater than that among dizygotic twins [6] [7]. Twin studies, however, only reveal segregating genes. If species-specific genes dominated carcinogenesis, they would be invisible in twin studies [8]. To be consistent with the age-distribution of risk, such genes must code for a discontinuous process.

For the common cancers, cross-sectional plots of cancer incidence rates versus age display an upward curvature that was initially interpreted as exponential [9] [10] [11]. This leads some to suggest that the less common cancers that exhibit a rise and fall in incidence rate over age, resulted from a different carcinogenic process [12]. But careful analyses demonstrated that age-distributions for all cancers studied display the same general shape [4] [5]. This commonality suggests that one explanation may apply to all or most cancers. What happens after age 30 for most common cancers may happen at younger ages for those cancers with a peak risk in youth or middle-age.

A theory of carcinogenesis should explain the role of aging. Why do some cancers occur in youth or middle-age while most occur in old age? It should explain why some tissues are more prone to cancer than others, and why one location, 
gender, race, or ethnicity is more or less vulnerable than another. It is the purpose of this paper to outline such a theory.

\section{Methods and Materials}

We analyzed data from reliable sources [13] [14], and included rates only from registries recording large numbers of cancers. The data are the most recent available, as the IARC has not published age-specific rates in print beyond 198892. In the following, numbers in parentheses indicate cases registered. For the 1983-87 era, data from the following 9 worldwide registries were utilized: United States: black males $(19,491)$, black females $(16,485)$, white males $(188,019)$, and white females (189,245); Puerto Rico: males $(17,391)$, and females $(14,405)$; Canada: males (235,610), and females (216,374); England, Birmingham and West Midlands: males $(46,504)$, and females $(44,049)$; Norway: males $(43,252)$, and females $(40,130)$; Australia New South Wales: males $(49,000)$, and females $(43,000)$; New Zealand Non-Maori: males $(25,612)$, and females $(25,305)$; Japan Osaka: males (59,720), and females (44,724); Japan Hiroshima for 1981-85: males (6579), and females (5418). For this era, Hiroshima was the largest Japanese registry other than Osaka without obvious flaws.

For the 1983-87 era, the following 6 US registries reported data for blacks and whites separately and were utilized: Alameda: white males (8120), white females (9432), black males (2139), and black females (1794); San Francisco: white males $(29,256)$, white females $(31,349)$, black males $(4146)$, and black females (3379); Connecticut: white males $(31,919)$, white females $(34,062)$, black males $(1751)$, and black females (1552); Atlanta: white males $(10,554)$, white females $(11,350)$, black males (3226), and black females (3049); New Orleans white males (7064), white females (6742), black males (3041), and black females (2739); Detroit: white males $(32,593)$, white females $(33,089)$, black males $(8997)$, and black females (7435). The US populations were utilized only for ASR and not age-distributions.

For the 1988-92 era, data from the following 9 worldwide registries were utilized: United States: black males $(23,703)$, black females $(19,226)$, white males $(228,834)$, and white females $(205,963)$; Puerto Rico males $(17,221)$, and females $(13,459)$; Canada: males $(277,113)$, and females $(249,710)$; Denmark: males $(65,749)$, and females $(69,302)$; Australia Victoria: males $(42,147)$, and females $(37,245)$; Japan Osaka: males $(71,714)$, and females $(51,579)$; Japan Miyagi males $(21,167)$, and females (15,579); Hong Kong: males $(47,477)$, and females $(36,291)$; China Tianjin: males $(18,825)$, and females $(15,649)$.

For the 1988-92 era, the following 7 US registries reported data for blacks and whites and/or Hispanic and non-Hispanic whites separately, and were utilized:

Los Angeles: non-Hispanic white males $(52,823)$, non-Hispanic white females $(50,373)$, Hispanic white males $(10,566)$, Hispanic white females $(11,550)$, black males (9484), and black females (8013); San Francisco: non-Hispanic white males $(32,418)$, non-Hispanic white females $(29,045)$, Hispanic white males (2859), Hispanic white females (2770), black males (4848), and black females 
(3773); Connecticut; white males $(37,761)$, white females $(37,185)$, black males (2128), and black females (1962); Atlanta: white males $(14,305)$, white females $(13,236)$, black males (4305), and black females (3896); New Orleans: white males (7895), white females (7270), black males (3296), and black females (3108); Detroit: white males $(38,629)$, white females $(34,825)$, black males $(10,525)$, and black females (8362): New Mexico: non-Hispanic white males (10,380), nonHispanic white females (8346), Hispanic white males (3287), and Hispanic white females (2896).

San Francisco reported separate data for Chinese (male $=1961$; female $=$ 1807) and Japanese (male $=358$; female $=437$ ) residents, as did Los Angeles: Chinese $($ male $=1178$; female $=1060)$ and Japanese $($ male $=1064$; female $=$ 1021). We analyzed this data.

Pearson correlation coefficients were calculated. The significance of these coefficients was determined by a t-test, where

$$
t=r\left(\text { square root of } n-2 / 1-r^{2}\right)
$$

Rates for deaths from all causes in the United States for 1989 were obtained from reference [15].

\section{Results}

1) Cancers

The median age-standardized rate, ASR, for each cancer is listed in Table 1 and Table 2. Cancer of the small intestine is rare, cancer of the mouth is uncommon, and cancers of the bronchus, colon, and rectum are common in all populations.

Table 1. Median ASR in worldwide populations.

\begin{tabular}{|c|c|c|c|c|}
\hline \multirow{2}{*}{ Cancer } & \multicolumn{2}{|c|}{$1983-87$} & \multicolumn{2}{|c|}{$1988-92$} \\
\hline & Males & Females & Males & Females \\
\hline Bronchus & 52.2 & 14.6 & 53.9 & 26.7 \\
\hline Colon & 24.5 & 20.3 & 23.7 & 19.4 \\
\hline Rectum & 15.7 & 9.2 & 13.9 & 8.9 \\
\hline Stomach & 13.5 & 6.2 & 14.1 & 6.1 \\
\hline Pancreas & 8.1 & 5.1 & 7.7 & 5.5 \\
\hline Kidney & 7.9 & 4.1 & 7.6 & 3.7 \\
\hline Esophagus & 5.4 & 2.1 & 9.1 & 2.2 \\
\hline Larynx & 5.3 & 0.7 & 5.7 & 1.1 \\
\hline Melanoma & 4.8 & 6.2 & 1.2 & 0.9 \\
\hline Liver & 2.5 & 1.1 & 5.3 & 2.1 \\
\hline Mouth & 2.4 & 1.1 & 2.5 & 1.2 \\
\hline Small Int. & 0.8 & 0.6 & 0.8 & 0.6 \\
\hline Breast & 0.5 & 61.5 & 0.4 & 56.2 \\
\hline
\end{tabular}


Table 2. Median ASR in the United States.

\begin{tabular}{|c|c|c|c|c|}
\hline \multirow{2}{*}{ Cancer } & \multicolumn{2}{|c|}{$1983-87$} & \multicolumn{2}{|c|}{$1988-92$} \\
\hline & Males & Females & Males & Females \\
\hline Bronchus & 87.8 & 34.5 & 85.1 & 36.2 \\
\hline Colon & 32.1 & 25.7 & 30.7 & 24.2 \\
\hline Rectum & 13.6 & 9.6 & 12.8 & 8.8 \\
\hline Stomach & 10.8 & 4.2 & 11.2 & 4.4 \\
\hline Pancreas & 10.1 & 6.8 & 8.8 & 7.1 \\
\hline Kidney & 10.1 & 4.6 & 12.1 & 6.1 \\
\hline Esophagus & 8.7 & 2.7 & 8.5 & 2.1 \\
\hline Larynx & 10.1 & 2.1 & 9.9 & 2.1 \\
\hline Melanoma & 4.4 & 3.4 & 4.4 & 2.5 \\
\hline Liver & 3.2 & 1.1 & 3.5 & 1.3 \\
\hline Mouth & 4.5 & 1.8 & 4.3 & 1.7 \\
\hline Small Int. & 1.1 & 0.7 & 1.4 & 1.1 \\
\hline Breast & 0.7 & 82.7 & 0.9 & 86.1 \\
\hline \multicolumn{5}{|c|}{$\begin{array}{l}\text { 1983-87, United States = black and white populations in Alameda, } \\
\text { San Francisco, Connecticut, Atlanta, New Orleans, and Detroit }\end{array}$} \\
\hline \multicolumn{5}{|c|}{$\begin{array}{l}\text { 1988-92, United States = black and white populations in Connecticut, } \\
\text { Atlanta, New Orleans, and Detroit, and Hispanic and non-Hispanic } \\
\text { white populations in Los Angeles, San Francisco, and New Mexico, } \\
\text { and black populations in Los Angeles and San Francisco }\end{array}$} \\
\hline
\end{tabular}

\section{2) Gender}

For cancers of the mouth, esophagus, stomach, small intestine, colon, rectum, liver, pancreas, larynx, bronchus, and kidney, the ASR for females is generally less than for males (Table 1 and Table 2). Cancer of the breast, is the most common cancer in females and the least common in males.

Is the rank order of cancers by ASR similar between the genders? To answer, we listed cancers with their ASR values in the same order in each population. We then listed populations in the same order for each gender and calculated the correlation coefficient for ASR values between the genders. We omitted breast cancer to avoid confusion from random variation in the small ASRs for males. For the worldwide populations, the correlation coefficient between the genders minus breast cancer is .912 in 1988-92, and .852 in 1983-87. For the American populations, the coefficient is .819 in 1988-92, and .927 in 1983-87. These coefficients are significant at $p<0.001$.

3) Race

Median ASRs are listed for blacks and whites in Table 3. ASRs for blacks are generally higher than for whites and conspicuously so for cancers of the stomach and esophagus. Rates for melanoma and breast cancer are higher for whites than blacks. 
Table 3. Median ASR in the United States.

\begin{tabular}{|c|c|c|c|c|}
\hline \multirow{2}{*}{ Cancer } & \multicolumn{2}{|c|}{$1983-87$} & \multicolumn{2}{|c|}{$1988-92$} \\
\hline & Black & White & Black & White \\
\hline Bronchus & 61.9 & 50.1 & 64.1 & 51.7 \\
\hline Colon & 29.9 & 27.8 & 29.4 & 25.1 \\
\hline Rectum & 9.9 & 11.4 & 10.1 & 10.6 \\
\hline Stomach & 9.7 & 5.1 & 10.1 & 4.5 \\
\hline Pancreas & 11.8 & 6.9 & 9.2 & 6.8 \\
\hline Kidney & 5.9 & 7.2 & 9.2 & 8.9 \\
\hline Esophagus & 8.3 & 2.7 & 8.1 & 2.8 \\
\hline Larynx & 6.9 & 4.7 & 6.7 & 4.7 \\
\hline Melanoma & 0.6 & 10.3 & 0.8 & 11.2 \\
\hline Liver & 2.5 & 1.6 & 2.8 & 2.2 \\
\hline Mouth & 3.3 & 3.1 & 3.6 & 2.7 \\
\hline Small Int. & 1.4 & 0.8 & 1.5 & 1.1 \\
\hline Breast & 32.8 & 39.6 & 36.9 & 43.9 \\
\hline & 1983-87, Uni & $\begin{array}{l}\text { Alameda } \\
\text { w Orlea }\end{array}$ & $\begin{array}{l}\text { o, Con } \\
\text { it }\end{array}$ & \\
\hline
\end{tabular}

Is the rank order of cancers by ASR similar between blacks and whites? We listed cancers with their ASRs in the same order in each population, and listed populations in the same order for blacks and whites. We omitted breast cancer as described above. The correlation coefficient between black and white ASRs is 0.960 for both 1988-92, and 1983-87.

Table 4 lists median ASRs by race and ethnicity. For cancers of the breast, bronchus, mouth, and larynx, the Chinese, Japanese, and Hispanic-white rates are lower than the black and non-Hispanic-white rates. For liver cancer, the opposite is true. The Chinese and Japanese rates for kidney cancer are low. The non-Hispanic-white rate for stomach cancer is low, and, for melanoma, high. The black rate for esophagus cancer is high. For cancers of the colon, rectum, and pancreas, Chinese and Hispanic-white rates are lower than the Japanese, black, and non-Hispanic-white rates.

For Chinese and Japanese, the risk for stomach, esophagus, and liver cancer is lower, and the risk for breast and colon cancer, higher in California than Asia.

4) Correlations among populations

Is the rank order of cancer ASRs similar in the different populations? We listed the cancers with their ASRs in the same order in each population and then calculated correlation coefficients between the populations in pair-wise combinations. Table 5 shows all such correlation coefficients are positive in 1983-87 era. Coefficients greater than 0.45 are significant $(p<0.05)$. Of the 45 coefficients in each era for the worldwide populations, 37 in 1988-92 and 33 in 1983-87 are 
Table 4. Median ASR in Los Angeles and San Francisco, 1988-92.

\begin{tabular}{cccccc}
\hline Cancer & non-Hisp. & Hispanic W & Black & Chinese & Japanese \\
\hline Bronchus & 49.5 & 27.1 & 66.5 & 30.3 & 23.2 \\
Colon & 24.5 & 16.3 & 31.4 & 19.2 & 26.4 \\
Rectum & 11.4 & 8.3 & 11.6 & 9.2 & 12.9 \\
Stomach & 5.4 & 9.4 & 10.6 & 9.3 & 16.6 \\
Pancreas & 7.1 & 5.8 & 10.8 & 4.4 & 7.1 \\
Kidney & 7.4 & 7.4 & 8.2 & 3.1 & 3.4 \\
Esophagus & 2.7 & 2.1 & 6.5 & 2.4 & 3.4 \\
Larynx & 3.7 & 2.1 & 5.8 & 0.9 & 0.8 \\
Melanoma & 11.4 & 2.7 & 0.7 & 0.3 & 0.8 \\
Liver & 2.1 & 4.5 & 3.7 & 11.1 & 4.5 \\
Mouth & 2.6 & 1.2 & 3.1 & 0.4 & 1.2 \\
Small Int. & 1.1 & 0.6 & 1.5 & 0.4 & 0.1 \\
Breast & 52.1 & 29.1 & 41.1 & 18.6 & 31.8 \\
\hline
\end{tabular}

Table 5. Correlation coefficients between world populations, 1983-87, for cancers in fixed order with ASR values.

\begin{tabular}{cccccccccc}
\hline & US B & PR & Osak & Nor & NSW & Can & Eng & Hiro & NZ \\
\hline US W & 0.925 & 0.889 & 0.305 & 0.953 & 0.936 & 0.985 & 0.936 & 0.283 & 0.95 \\
US B & - & 0.799 & 0.414 & 0.843 & 0.859 & 0.968 & 0.97 & 0.351 & 0.867 \\
PR & - & - & 0.483 & 0.915 & 0.812 & 0.871 & 0.851 & 0.51 & 0.846 \\
Osak & - & - & - & 0.396 & 0.308 & 0.384 & 0.502 & 0.968 & 0.316 \\
Nor & - & - & - & - & 0.954 & 0.943 & 0.906 & 0.414 & 0.971 \\
NSW & - & - & - & - & - & 0.935 & 0.898 & 0.298 & 0.986 \\
Can & - & - & - & - & - & - & 0.977 & 0.352 & 0.949 \\
Eng & - & - & - & - & - & - & - & 0.464 & 0.903 \\
Hiro & - & - & - & - & - & - & - & - & 0.317 \\
\hline
\end{tabular}

US W = United States white; US B = United States black; PR = Puerto Rico; Osak = Osaka; Nor = Norway; NSW = New South Wales; Can = Canada; Eng = England, Birmingham; Hiro = Hiroshima; NZ = New Zealand, non-Maori

significant. The correlation between the two Japanese populations is high $(\mathrm{r}=$ 0.968), but between the Japanese populations and the non-Japanese populations are moderate or low. For the 1988-92 era, the correlations between the two Chinese populations and between the two Japanese populations are high $(>0.90)$, but the correlations between the Chinese and Japanese populations $(r<0.752)$ are only moderate. Among the 45 coefficients in each table, the median $r$, with 5 - 95 percentile range in parentheses, is $0.722(0.383$ - 0.985) for 1988-92, and .867 (0.306 - 0.976) for 1983-87.

5) Correlations among cancer ASRs

For the worldwide populations in each era, we calculated correlation coeffi- 
cients between ASRs for cancers of the mouth, esophagus, stomach, small intestine, colon, rectum, liver, pancreas, larynx, bronchus, and kidney as well as melanoma in all pair-wise combinations. Values less than 0.45 are insignificant. Of the 66 correlation coefficients in each era, 34 from 1988-92, and 30 from 1983-87 are significant. Of these significant coefficients, the median is .688 for 1988-92, and 0.665 for $1983-87$.

All negative coefficients are insignificant. For the worldwide populations across both eras, all coefficients with melanoma are insignificant, with one modest exception.

We calculated the same correlation coefficients for the American populations. Of the 66 American coefficients in each era, 51 from 1988-92 and 50 from 1983-87 are positive. No negative correlations are significant. Of the 7 positive correlations with melanoma in the American populations across both eras, only one is significant.

Only three correlation coefficients are strong $(r>0.700)$ in both eras and in both the worldwide and American populations: larynx vs bronchus, larynx vs mouth, and larynx vs kidney.

The correlation coefficient between the distribution of cancer $\mathrm{X}$ cancer correlation coefficients between the two era is $0.887(p<0.001)$ for the worldwide populations and $0.636(p<0.001)$ for the American populations.

6) Comparing the risk of aging with other-than-aging processes

For each cancer, the difference in ASR (dASR) between populations measures risk from other-than-aging causes. For each cancer, the difference in age-specific rates between ages 70 and 30 (d70 - 30) measures risk from aging causes. Agespecific rates are reported in 5-year age-intervals, e.g., 30 - 34, 35 - 39, 40 - 44, etc. For simplicity, we identified intervals by their first number: age $30-34=$ age 30. Table 6 shows the comparison between the two risks. Except for melanoma and liver cancer, the maximum dASR is less than the median $\mathrm{d} 70$ - 30. For melanoma and liver cancer, the maximum dASR is less than the $90^{\text {th }}$ percentile $\mathrm{d} 70$ - 30. The percentage of median $\mathrm{d} 70$ - 30 equal to maximum dASR is listed for each cancer in Table 6 . The correlation coefficient between the lists of percent median between the two eras is $.887(p<0.001)$.

7) The Critical Age

For each cancer in each of the worldwide populations, the age-specific incidence rates were listed at ages $30,40,50,60,70$, and 80 . For each era, the differences were calculated between adjacent rates: d40 - 30, d50 - 40, d60 - 50, d70 60 , and d80 - 70. In the 1988-92 era, Puerto Rico did not report rates beyond age 75. For each cancer, these differences were listed with the respective ASR values. Correlation coefficients were calculated between the lists of adjacent differences and ASR values. Table 7 shows these coefficients along with the median agespecific rates. In both eras, the highest coefficient, .900 in 1983-87, and .886 in 1988-92, is between d50 - 40 and ASR despite the fact that cancer incidence is rare at ages 40 and 50 .

For each cancer in each of the worldwide populations, the male-female 
Table 6. Comparison of Median d70-30 and Maximum dASR, 1983-87.

\begin{tabular}{|c|c|c|c|}
\hline Cancer & d70 - 30 Median & dASR Maximum & Percent Median \\
\hline \multicolumn{4}{|l|}{ Males } \\
\hline Colon & 198.5 & 18.8 & 9.5 \\
\hline Pancreas & 65.5 & 6.3 & 9.6 \\
\hline Rectum & 109.7 & 13.1 & 11.9 \\
\hline Kidney & 51.3 & 6.6 & 12.9 \\
\hline Breast & 3.4 & 0.5 & 14.7 \\
\hline Larynx & 36.9 & 5.6 & 15.2 \\
\hline Bronchus & 440.1 & 72.2 & 16.4 \\
\hline Esophagus & 45.9 & 11.3 & 24.6 \\
\hline Small Intest. & 3.9 & 1.2 & 30.8 \\
\hline Mouth & 12.2 & 5.1 & 41.8 \\
\hline Stomach & 114.6 & 77.8 & 67.9 \\
\hline Melanoma & 12.7 & 25.7 & 202.4 \\
\hline Liver & 17.5 & 39.9 & 228.1 \\
\hline \multicolumn{4}{|l|}{ Females } \\
\hline Colon & 141.6 & 20.4 & 14.4 \\
\hline Pancreas & 45.9 & 8.2 & 17.9 \\
\hline Rectum & 67.3 & 6.7 & 10.1 \\
\hline Kidney & 20.8 & 3.6 & 17.3 \\
\hline Breast & 223.3 & 67.3 & 30.1 \\
\hline Larynx & 3.3 & 1.8 & 54.5 \\
\hline Bronchus & 113.4 & 24.1 & 21.3 \\
\hline Esophagus & 16.8 & 2.8 & 16.7 \\
\hline Small Intest. & 4.4 & 0.5 & 11.4 \\
\hline Mouth & 4.6 & 1.2 & 26.1 \\
\hline Stomach & 45.2 & 35.4 & 78.3 \\
\hline Melanoma & 7.3 & 23.6 & 323.3 \\
\hline Liver & 6.8 & 9.1 & 133.8 \\
\hline
\end{tabular}

Table 7. Correlation coefficients between adjacent age-specific rate differences and ASR, world populations.

\begin{tabular}{ccccc}
\hline & Median & Age & \multicolumn{2}{c}{ Correlation Coefficients } \\
\cline { 3 - 4 } Age & Rate & Difference & $1983-87$ & $1988-92$ \\
\hline 30 & 0.5 & $40-30$ & 0.771 & 0.665 \\
40 & 2.7 & $50-40$ & 0.899 & 0.886 \\
50 & 9.6 & $60-70$ & 0.865 & 0.854 \\
60 & 22.4 & $70-60$ & 0.789 & 0.779 \\
70 & 39.6 & $80-70$ & 0.458 & 0.339 \\
80 & 47.5 & & & \\
\hline
\end{tabular}


difference in $\mathrm{d} 50$ - 40 was calculated along with the male-female difference in ASR. The correlation coefficient between these two gender differences over all cancers is 0.897 in 1983-87, and 0.944 in 1988-92.

For each cancer in American black and white populations, the black-white difference in $\mathrm{d} 50$ - 40 was calculated along with the black-white difference in ASR. The correlation coefficient between these two racial differences over all cancers is 0.946 in 1983-88, and 0.921 in 1988-92.

For each cancer in the Los Angeles, San Francisco, and New Mexico populations in the 1988-92 era, the Hispanic white-non-Hispanic white difference in d50 - 40 was calculated along with the Hispanic white-non-Hispanic white difference in ASR. The correlation coefficient between these ethnic differences over all cancers is 0.974 .

For each cancer in Osaka, Miyagi, Hong Kong, and Tianjin in the 1988-92 era, the Osaka-Tianjin, Osaka-Hong Kong, Miyagi-Tianjin, and Miyagi-Hong Kong differences in $\mathrm{d} 50$ - 40 were calculated along with the respective differences in ASR. The correlation coefficients between these ethnic differences over all cancers are, respectively, $0.900,0.900,0.946$, and 0.842 .

8) Risk of cancer and death from all causes

The all-sites ASRs for Chinese, Japanese, blacks, Hispanic whites, and nonHispanic whites of each gender were averaged between Los Angeles and San Francisco for 1988-92. Correlation coefficients were calculated between the lists of all-sites ASRs and all-cause death rates for Asians, blacks, Hispanics, and whites in America in 1989 (Elo and Preston, 1997) [15]. When the Chinese allsite ASR is paired with the Asian all-cause death rate, the correlation coefficients between all-site ASR and all-cause death rate for ages 60, 70, and 80 are 0.886, 0.924 , and 0.917 , respectively. When Japanese all-site ASR is paired with the Asian all-cause death rate, the coefficients are $0.894,0.934$, and 0.941 , respectively.

\section{Discussion}

Except for the unusual risk for stomach, esophagus, and liver cancer in China and Japan, the populations studied exhibit similar rank order of cancer ASRs suggesting a similar carcinogenic process in all populations.

The consistently strong positive correlation coefficients $(r>0.700)$ between cancers of the larynx and bronchus, larynx and mouth, and larynx and kidney suggest a common carcinogen, e.g., tobacco or alcohol, for these tissues.

The insignificant, and often negative, coefficients between melanoma and the other cancers suggest that melanoma responds to a unique carcinogen, e.g., sunlight, which may offer weak protection against other cancers.

The modest or weak correlation coefficients among cancers of the esophagus, stomach, small intestine, colon, rectum, liver, and pancreas suggest that less than half the ASRs for these cancers is caused by common carcinogens. But the strong or moderate coefficients between distributions of the cancer $\mathrm{X}$ cancer correlation coefficients between eras argue against a random distribution of $r$-values. Cancers 
are common or rare for a reason, and more than half that reason tends to be unique to each cancer.

For cancers of the mouth, esophagus, small intestine, colon, rectum, pancreas, larynx, bronchus, breast, and kidney, the maximum dASR is less than $55 \%$ of the median $\mathrm{d} 70$ - 30. For melanoma and cancers of the stomach and liver, maximum dASR is less than $90 \%$ of $\mathrm{d} 70-30$.

The high correlation coefficient between d50 - 40 and ASR suggests that the transition, over these years, from minimal to increasing risk can explain some $80 \%$ of ASR. That same transition can also explain the differences in ASR between genders, races, and ethnicities.

Why is cancer more common in one tissue than another, or in one gender or race or ethnicity than the other(s)? Because the difference in age-specific rates between ages 50 and 40 is greater for the more common than the less common tissue, gender, race, or ethnicity.

What happens between ages 40 and 50? We suspect the carcinogenic target is created, and that the size of the target determines the size of the risk.

Height correlates with cancer risk [16]. We suspect height is a surrogate for target size. Men get more cancer than women because they harbor bigger targets. The larynx is an example. It's bigger in men than in women [17]. And we think that's why larynx cancer is 6-fold more common in men than women.

The breast is a dramatic exception to the rule that men are more prone to cancer. But women have bigger breasts and, therefore, bigger cancer targets than men, and the bigger a woman's breast, the bigger the risk of cancer [18] [19]. Kleinfelter's patients have larger breasts and larger breast cancer risk than normal men, but smaller breasts and breast cancer risks than normal women [20].

The thyroid, like the breast, is more vulnerable to cancer in women than men. The female thyroid grows with the menstrual cycle [21] [22]. We suspect this growth presents a bigger target for carcinogenesis.

The smallest difference in cancer risk between the genders is for small intestine, followed by pancreas. No correlation, or only a weak correlation, exists between body height and size of the small intestine and pancreas [23] [24].

Why is cancer of the small intestine rare while cancers of the stomach and colon are common? Only the small intestine is coated with villi and we suspect they conceal the targets of carcinogenesis.

Why is cancer of the mouth less common that cancer of the esophagus, stomach, colon, and rectum? Oral stem cells age slower than other stem cells, and we suspect the mouth target emerges more slowly than do the targets in other tissues.

Carcinogenesis is a stem cell phenomenon [25]. And each tissue has a unique strategy for stem cells tailored to the regenerative needs of that tissue [26]. We suspect this strategy is key to target formation.

Why don't hearts get cancer? Cardiomyocytes don't regenerate [27]. Why are sarcomas rare relative to carcinomas? Regeneration is rare in the tissues of sarcoma origin relative to those of carcinoma origin. Tissue generation is safe, but 
both regeneration and delayed differentiation are risky.

Male germ cells [28] breast glandular cells [29] [30], and colonic crypt cells [31] that fail to mature are prone to cancer. So are melanocytes that fail to make melanin [32]. The black-white difference in melanoma risk has been attributed to protection from UV-radiation [33]. But lightly-pigmented Chinese and Japanese offer the same protection as blacks. Even Hispanic whites are at a quarter risk of non-Hispanic whites, and even non-Hispanic whites, who tan well in response to UV exposure, are at low risk compared to non-Hispanic whites who fail to $\tan$ [34]. It may be more the making of melanin than the blocking of UV that protects from melanoma.

Once tissue differentiation has occurred, the stem cells that remain seem refractory to carcinogenesis [35]. Normal testes, thoroughly utilized breasts, and pigmented skin are at low cancer risk. We speculate that regeneration becomes dangerous when it becomes excessive, causing refractory stem cells to be replaced by pluripotential stem cells from tissue dedifferentiation [36]. Perhaps the target of carcinogenesis consists of the number of such dangerous stem cells, and, perhaps, $\mathrm{d} 50$ - 40 reflects this number.

Excessive regeneration would follow from excessive tissue injury. But excessive tissue injury is always the cause of death. If excessive regeneration were the principal cause of cancer, the all-site ASR should correlate with the rate of death from all causes. We have found that correlation to be greater than 0.90 at ages 70 and 80 .

Cells become senescent at old ages and the regeneration that is the essence of wound healing declines [37]. This would explain the decline in cancer risk at old ages [38].

If target size contributes to risk, inhibiting growth, perhaps, with somatostatin, might be beneficial. If excessive injury contributes to risk, adopting womanly behavior, particularly in the manner of Hispanic and Asian woman, might be beneficial [39].

\section{Ethics}

This paper is solely an analysis of statistics collected by reputable sources. No humans or animals were utilized by the authors.

\section{Conflict}

There is no conflict of interest.

\section{References}

[1] Tomassetti, C. and Vogelstein, B. (2015) Variation in Cancer Risk among Tissues Can Be Explained by the Number of Stem Cell Divisions. Science, 347, 78-81. https://doi.org/10.1126/science.1260825

[2] Potter, J.D. and Prentice, R.L. (2015) Cancer Risk: Tumors Excluded. Science, 347, 727. https://doi.org/10.1126/science.aaa6507

[3] Wu, S., Powers, S., et al. (2016) Substantial Contribution of Extrinsic Risk Factors to Cancer Development. Nature, 529, 43-47. https://doi.org/10.1038/nature16166 
[4] Dix, D. (2015) On the Causes of Cancer. The Argument for Inheritance. International Journal of Health Sciences, 3, 1-6 https://doi.org/10.15640/ijhs.v3n3al

[5] Dix, D. (1989) On the Role of Aging in Cancer Incidence. Journal of Gerontology, Biological Sciences, Special Issue, 44, 10-18.

[6] Lichtenstein, P.l., Holm, N.V., et al. (2000) Environmental and Heritable Factors in the Causation of Cancer-Analysis of Cohorts of Twins from Sweden, Denmark, and Finland. The New England Journal of Medicine, 343, 78-85.

[7] Mucci, L., Hjelmborg, J.B., Harris, J.A., et al. (2016) Familial Risk and Heritability of Cancer among Twins in Nordic Countries. JAMA, 315, 68-76.

https://doi.org/10.1001/jama.2015.17703

[8] Dix, D. (2003) On the Role of Genes Relative to the Environment in Carcinogenesis. Mechanisms of Ageing and Development, 124, 323-332. https://doi.org/10.1016/S0047-6374(02)00113-6

[9] Nordling, C.O. (1953) A New Theory on the Cancer-Inducing Mechanism. British Journal of Cancer, 7, 68-72. https://doi.org/10.1038/bjc.1953.8

[10] Armitage, P. and Doll, R. (1954) The Age-Distribution of Cancer and a Multi-Stage Theory of Carcinogenesis. British Journal of Cancer, 8, 1-12. https://doi.org/10.1038/bjc.1954.1

[11] Dix, D., Cohen, P. and Flannery, J. (1980) On the Role of Aging in Cancer Incidence. Journal of Theoretical Biology, 83, 163-173. https://doi.org/10.1016/0022-5193(80)90377-X

[12] Nejako, A., Aranton, B. and Dix, D. (2005) Carcinogenesis: A Cellular Model for the Age-Dependence. Anticancer Research, 25, 1385-1390.

[13] Parkin, D.M. Muier, C.S., et al. (1992) Cancer Incidence in Five Continents. Volume VI, International Agency for Research on Cancer, Lyon.

[14] Parkin, D.M., Whelan, S.L., et al. (1998) Cancer Incidence in Five Continents. Volume VII, International Agency for Research on Cancer, Lyon.

[15] Elo, L.T. and Preston, S.H. (1997) Racial and Ethnic Differences in Mortality at Older Ages. In: Martin, Ed., Racial and Ethnic Differences in the Health of Older Americans, National Research Council (US) Committee on Population, National Academies Press, Washington DC.

[16] Kabat, C.G., Anderson, M.L., et al. (2013) Adult Stature and Risk of Cancer at Different Anatomic Sites in a Cohort of Postmenopausal Women. Cancer Epidemiology, Biomarkers \& Prevention, 22, 1353-1363. https://doi.org/10.1158/1055-9965.EPI-13-0305

[17] Inamoto, Y., Saitoh, E., et al. (2015) Anatomy of the Larynx and Pharynx: Effects of Age, Gender, and Height Revealed by Multidetector Computed Tomography. Journal of Oral Rehabilitation, 42, 670-677. https://doi.org/10.1111/joor.12298

[18] Jansen, L.A., Backstein, R.M. and Brown, M.H. (2014) Breast Size and Breast Cancer: A Systematic Review. Journal of Plastic, Reconstructive \& Aesthetic Surgery, 67, 1615-1623.

[19] Hsieh, C.C. and Trichopoulos, D. (1991) Breast Size, Handedness and Breast Cancer Risk. European Journal of Cancer and Clinical Oncology, 27, 131-135. https://doi.org/10.1016/0277-5379(91)90469-T

[20] Brinton, L.A. (2011) Breast Cancer Risk among Patients with Klinefelter Syndrome. Acta Paediatrica, 100, 814-818. https://doi.org/10.1111/j.1651-2227.2010.02131.x

[21] Hegedis, L., Karstaup, S. and Rasmussen, N. (1986) Evidence of Cyclic Alterations of Thyroid Size during the Menstrual Cycle in Healthy Women. American Journal 
of Obstetrics and Gynecology, 155, 142-145.

https://doi.org/10.1016/0002-9378(86)90098-0

[22] Fister, P., Gaberscek, S., Zaletel, K., et al. (2009) Thyroid Volume Changes during Pregnancy and after Delivery in an Iodine-Sufficient Republic of Slovenia. European Journal of Obstetrics \& Gynecology and Reproductive Biology, 145, 45-48.

[23] Hosseinpour, M. and Behdad, A. (2008) Evaluation of Small Bowel Measurement in Alive Patients. Surgical and Radiologic Anatomy, 30, 653-655. https://doi.org/10.1007/s00276-008-0398-2

[24] Cager, V., Kumral, B., et al. (2014) Study of Volume, Weight and Size of Normal Pancreas, Spleen, and Kidney in Adults Autopsies. Forensic Medicine and Anatomy Research, 2, 63-69. https://doi.org/10.4236/fmar.2014.23012

[25] Beachy, P.A., Karhadkar, S. and Berman, D.M. (2004) Tissue Repair and Stem Cell Renewal in Carcinogenesis. Nature, 432, 324-331. https://doi.org/10.1038/nature03100

[26] Blanpain, C. and Fuchs, E. (2014) Plasticity of Epithelial Stem Cells in Tissue Regeneration. Science, 344, 1242281. https://doi.org/10.1126/science.1242281

[27] Murry, C.E. and Lee, R.T. (2009) Turnover after the Fallout. Science, 324, 47-48. https://doi.org/10.1126/science.1172255

[28] Hoi-Hansen, C.E., Rajpert-De Meyts, E., Daugaard, G. and Skakkebaek, N.E. (2005) Carcinoma in Situ Testes, the Progenitor of Testicular Germ Cell Tumors: A Clinical Review. Annals of Oncology, 16, 863-868. https://doi.org/10.1093/annonc/mdi175

[29] Ruso, J., Moral, R.M., et al. (2005) The Protective Role of Pregnancy in Breast Cancer. Breast Cancer Research, 7, 131-142. https://doi.org/10.1186/bcr1029

[30] Britt, K., Ashworth, A. and Smalley, M. (2007) Pregnancy and the Risk of Breast Cancer. Endocrine-Related Cancer, 141, 907-933.

[31] Boman, B.M., Fields, J.Z. and Cavanaugh, K.L. (2008) How Dysregulation of Colonic Crypt Dynamics Cause Stem Cell Overpopulation and Initiate Colon Cancer. Cancer Research, 68, 3304-3306. https://doi.org/10.1158/0008-5472.CAN-07-2061

[32] Engleand, A., Tretl, S., Akslen, L.A. and Bjørge, T. (2006) Body Size Thyroid Cancer in Ten Million Norwegian Men and Women. British Journal of Cancer, 95, 366-370. https://doi.org/10.1038/sj.bjc.6603249

[33] Lo, J.A. and Fisher, D.E. (2014) The Melanoma Revolution: From UV Carcinogenesis to a New Era in Therapeutics. Science, 346, 945-949.

[34] Merrill, R.M., Pace, N.D. and Elison, A.N. (2010) Cutaneous Malignant Melanoma among Hispanics and Non-Hispanics in the United States. Ethnicity \& Disease, 20, 353-358.

[35] Pattabiraman, D.R., Bierie, B., et al. (2016) Activation of PKA Leads to Mesenchymal-to-Epithelial Transition and Loss of Tumor-Initiating Ability. Science, 351, aad3680. https://doi.org/10.1126/science.aad3680

[36] Bourahdi, S. and Blanpain, C. (2016) Tracking the Origins of Tumorigenesis. Science, 351, 453-454. https://doi.org/10.1126/science.aad9670

[37] Lei, M. and Chuong, C.-M. (2016) Aging, Alopecia, and Stem Cells. Science, 351, 559-560. https://doi.org/10.1126/science.aaf1635

[38] Rodriquez-Rodero, S., Fernandez-Morera, J.L., et al. (2011) Aging Genetics and Aging. Aging and Disease, 2, 186-195.

[39] Dix, D. (2014) The Female Health-Survival Advantage: Paradox Unwarranted. International Journal of Public Health, 59, 213. 
Submit or recommend next manuscript to OALib Journal and we will provide best service for you:

- Publication frequency: Monthly

- 9 subject areas of science, technology and medicine

- Fair and rigorous peer-review system

- Fast publication process

- Article promotion in various social networking sites (LinkedIn, Facebook, Twitter, etc.)

- Maximum dissemination of your research work

Submit Your Paper Online: Click Here to Submit

Or Contact service@oalib.com 